\title{
COMMENTARY
}

\section{Using Team Innovation and Networking to Respond to Rapid Changes in the Academy}

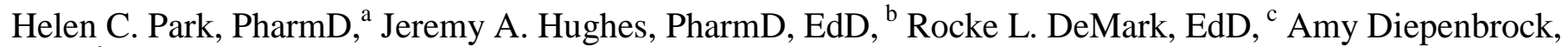 \\ $\mathrm{PhD},{ }^{\mathrm{d}}$ Katie S. McClendon, PharmD ${ }^{\mathrm{e}}$ \\ ${ }^{a}$ Roseman University of Health Sciences, College of Pharmacy, Henderson, Nevada \\ ${ }^{\mathrm{b}}$ Chicago State University, College of Pharmacy, Chicago, Illinois \\ ${ }^{c}$ Chapman University, School of Pharmacy, Irvine, California \\ ${ }^{\mathrm{d}}$ University of the Incarnate Word, Feik School of Pharmacy, San Antonio, Texas \\ ${ }^{\mathrm{w}}$ University of Mississippi, School of Pharmacy, Jackson, Mississippi
}

Corresponding Author: Helen C. Park, Roseman University of Health Sciences, College of Pharmacy, 11 Sunset Way, Henderson, NV 89014. Tel: 702-968-5248. Email: hpark1@ roseman.edu

Submitted March 26, 2021; accepted September 8, 2021; ePublished September 2021

When COVID-19 shuttered schools across the nation, it propelled higher education institutions into uncharted territories. Institutions had to make rapid decisions in a short period of time with limited information or direction. In these uncertain and challenging times, members of the academy reached out to one another to discuss, share, and learn from one another. What began with a few members of the Student Services Personnel Special Interest Group (SIG) grew to many members who banded together through open discussions to utilize a team approach to innovative problem-solving. Working together through open discussions created a setting that promoted diverse ideas, multiple perspectives, and a depth of knowledge to address some of the most challenging issues pharmacy education has had to overcome. When partnering together, institutions had a much greater resource of knowledge and support that could be leveraged to broadly benefit the academy.

Keywords: open discussion, student affairs, networking, COVID-19, SIG

\section{INTRODUCTION}

Higher education, and pharmacy education in particular, is in a constant state of change. Pharmacy educators have been adaptive, finding innovative means to address the many challenges encountered inside both classrooms and pharmacies in a rapidly changing world. Despite this flexibility, few were fully prepared to act quickly when the global COVID-19 pandemic gripped the United States. ${ }^{1}$ The large-scale shift to remote life had a profound impact on education at the beginning of the pandemic. ${ }^{2}$ For pharmacy institutions that rely upon traditional in-person interactions and classroom learning, significant changes to teaching, clinical work, assessment, professional development, recruitment, and student support had to be drastically altered. Any changes in these areas would normally take months, if not years, to implement. Members of the academy were forced to make decisions in a matter of days or hours. This urgent and essential effort required the full-scale attention of all administrators, faculty, and staff. The main focus of any institution should be on the education of its students. As a result, the priority for most schools at the outset of the pandemic was to determine how to provide high quality and effective teaching in a remote environment. ${ }^{3}$ This priority did not negate other institutional responsibilities.

Student affairs professionals largely oversee the non-academic matters of the institution, from recruitment and admissions to student support and career operations. Attempting to manage these responsibilities during a pandemic when many institution resources were exhausted was daunting. Without the familiar means of internal support during what was an unprecedented and chaotic period, the germination of a successful idea started to take shape within the AACP Student Services Personnel SIG. It was during the first days of the pandemic where members of the SIG's Executive Committee began communicating frequently to provide professional and personal support. The conversations focused on how each SIG officer was processing the changes to daily lives and approaching student services. These discussions were highly effective, providing opportunities to brainstorm new ideas and processes that would better serve student populations. As the frequency of meetings increased and their utility affirmed, the Executive Committee decided to expand the open discussions to all members of the SIG under the presumption that most were feeling similarly overwhelmed and uncertain about how to proceed with their responsibilities. A semi-structured open discussion series would provide an outlet to showcase best practices while creating a large support network. 
Based on attendance and participant engagement, the Student Services Personnel SIG open discussion series was well received, with individuals across the country participating in frequent discussions that focused on topics such as commencement and admissions. With the success of the Student Services open discussion series, there was an opportunity to explore its broad application outside of the Student Services Personnel SIG environment. Organizational and learning theories provide context for why the open discussion series can be an effective approach to engaging and educating individuals in professional organizations. A goal of this commentary is to provide a methodology for formalizing collaboration and information sharing efforts through existing professional associations and special interest groups.

\section{Development of the Open Discussion Series}

Faced with a constant flow of change and uncertainty, it was immediately clear that the traditional unidirectional webinar format to convey information would be insufficient. ${ }^{4}$ Informal connections and idea sharing formed organically across many educational sectors, including both formal and informal networking through consortia, special interest groups, and programs with similar characteristics. No one had all the answers and the moderators, cognizant of this, wanted to offer a forum for colleagues across the academy to listen, share, and take ideas back to their respective campuses. Existing association webinar platforms and guidelines had time limits and planning requirements that were not conducive to the fluid nature of the situation. Moving to the Zoom web-conferencing platform provided the structure and flexibility needed to conduct these sessions. Allowing participants to be on camera and contribute created buy-in and fostered an environment where individuals were part of the process and solutions. Sessions were designed around themes and subtopics in a semi-structured format to maximize the effectiveness of the discussions (see table 1). The Executive Committee developed a set of standard PowerPoint slides that would guide each session. An agenda for each session included an introduction of leadership in attendance, explanation of the open discussion series and format, and preset topics to be discussed. For each discussion, a member of the Executive Committee was designated to kick off the first topic with an example of what their institution was doing to address such issues. From there, open flow and interactive dialogue was encouraged through moderated chat and voice participation. Each session ended with a reminder of the topics to be discussed at the following discussion. The Zoom platform and member-initiated sessions allowed for flexibility if sessions exceeded the allotted time. Finally, recordings were shared through the AACP Connect site shortly after the session for SIG members who were unable to attend.

The ability to have timely, dynamic discussions on topics that all institutions were facing contributed to the success of the open discussions. The speed at which change occurred made it critical to have conversations in real-time. The open discussion forum allowed for a group of student services administrators and other knowledgeable contributors to convene and essentially "crowdsource" solutions to the challenges they were facing. There was a shared sentiment of collaboration that allowed for a support system among the professionals who support students.

During the fall 2020 term, most higher education institutions continued delivering courses virtually. Knowing challenges and new issues would arise throughout the term, the SIG officers made a decision to institutionalize open discussions into the SIG committee responsibilities moving forward and continue the series. The SIG Programming Committee hosted three open discussions on evolving topics (see table 1). Anecdotal feedback from members indicated they continued to be appreciative of this interactive format allowing for on-the-spot troubleshooting in the ever-changing landscape of pharmacy education.

\section{Informing the Process}

After identifying the desired outcomes of sharing best practices and innovative approaches for adapting to rapid shifts in the learning environment, the process was informed through evidence-based strategies for facilitating innovation from organizational theory. Team innovation principles were incorporated into the model design through intentional inclusion of diversity of thought and experience at both the facilitator and participant level. ${ }^{5}$ This included representation from differing program types (public versus private institutions and accelerated versus four-year Pharm.D. programs), institution locations (as local and state ordinances impacted operating abilities at the state, county, and city level), and individuals with varying job titles, responsibilities, and levels of experience. Strategies of incremental innovation were incorporated by modifying existing platforms, reflecting on ways to merge the accessibility of webinars and the interactivity of round-table models into a dynamic and approachable system. ${ }^{5,6}$ The principles of process innovation were included by applying existing webinar templates and communication strategies (such as AACP Connect, email blasts, and webinar tag-ons) to the new model ${ }^{5,6}$. The online discussion forum allowed for a free exchange of ideas through facilitated video discussion with rapid resource sharing through the chat feature, allowing for cross-academy idea sharing and exploration that further promoted team innovation on a larger scale. Ground rules were shared at the start of each discussion session, to promote the formation of a Quality Learning Environment, promoting feelings of psychological 
safety and trust. ${ }^{7,8,9}$ Additional elements of leadership and education theory, including team formation, norming, change management, grief/loss, and resiliency further informed the process. ${ }^{10,11,12,13,14}$

Communities of practice (CoP) use the principles of team innovation by creating groups to support collective learning. ${ }^{15}$ These groups may gather together at a regularly scheduled meeting or have a looser organizational structure. The three components of a CoP are domain, community, and practice. In the open discussions hosted by the Student Services SIG, the sessions met all three characteristics:

a. Domain: CoP have a shared domain of interest. In the open discussions, attendees were interested in learning more about how other institutions were handling the disruption that arose from COVID-19.

b. Community: CoP share information and learn from each other in a mutually beneficial format. Unlike webinars and lectures which feature experts, members of a $\mathrm{CoP}$ (attendees of the open discussions) build rapport and support each other via problem-solving and sharing experiences.

c. Practice: CoP are composed of those who not only have an interest in a domain, but who also "practice" or work in that area. The attendees of the open discussions were not attending for theoretical knowledge growth, but to be able to apply the solutions discussed at their institutions .

CoP have historically thrived among those who met in person, but online CoP have also developed. Karam et al describe the use of online CoP among K-12 science teachers, since schools often only have a few teachers who share similar teaching responsibilities and expertise. Much like a high school with only one physics teacher, schools/colleges of pharmacy frequently employ limited personnel who work in student services, which hinders their ability to learn from peers in their daily work environments. ${ }^{16}$ Additionally, since COVID-19 led to rapid transformation in higher education and health care in Spring 2020, slower means of sharing expertise (such as publications, annual organization meetings, webinars) would have delayed informing necessary innovations at other institutions.

\section{Recommendations for Open Discussions}

Contributing characteristics for successful open discussions and recommendations to launch these events were identified and are described in Table 2. First and foremost, the authors recommend holding open discussion. During times of crises, it is difficult to navigate and identify the best course of action. This can be an overwhelming period in which organizing and facilitating a discussion may feel onerous. However, institutions can benefit most from collaboration and shared knowledge at this stage. The key is to create the opportunity to start the conversation. The results will yield farreaching benefits across multiple institutions, including moral support among colleagues.

Second, facilitators should model vulnerability and create a safe space for open discussion. Members were hesitant to share their thoughts on ways to handle student issues during the pandemic. To facilitate the conversation, moderators would start by acknowledging that they were not experts in this area and that they were also learning. Innovative solutions were borne from brainstorming sessions where participants felt comfortable to provide insight. Conversely, moments of awkward silence will arise and should be expected. In these situations, moderators should encourage dialogue from attendees, whether on-camera or via chat functions.

Third, flexibility and open-mindedness are imperative in the open discussion planning. Mapping out topics in advance is helpful, but a key success factor is to allow for timely and relevant matters to supersede planned topic discussions. Attendees will benefit from discussing the most pressing issues of the moment to collectively develop best practices for unprecedented situations. Having a semi-structured format provides organization but still allows time for organic innovation and idea sharing.

Finally, open discussions amplify the "phone a friend" phenomenon and the power of one's network and CoP. There are many known benefits that stem from networking. During challenging times, it is helpful to call upon your network of colleagues, experts, and friends. As informal groups can form quickly and organically to address uncertainty and the need for change, the authors recognize that other networks also began to develop additional structure in response to the crisis. The open discussion sessions provided organized meetings that engaged SIG members' primary and secondary networks in finding solutions to mutually shared issues.

\section{CONCLUSION}

Despite the tumultuous conditions under which the open discussion series was created, this forum proved to be an instrumental platform for pharmacy educators to quickly convene, discuss urgent and relevant matters as they were occurring, and develop solutions derived from the collective wisdom of a greater group. During a time of crisis, the ability to rapidly respond and consider non-traditional solutions is crucial. The COVID-19 crisis created an opportunity for pharmacy educators and administrators to organically form CoPs through the SIG's open discussions, which served needs beyond that of an individual institution. The circumstances required unprecedented solutions, and over the last year, 
pharmacy educators responded collectively and effectively made decisions that will mark this period of history in pharmacy education.

\section{ACKNOWLEDGEMENTS}

The authors gratefully acknowledge the members of the AACP Student Services Personnel Special Interest Group for participating in the open discussions. We all benefited from SIG's willingness to share ideas and collectively develop best practices in an effort to best serve our students and support pharmacy education. Additionally, the authors appreciate members of the SIG Programming Committee for their leadership with the second round of Open Discussions.

\section{REFERENCES}

1. Romanelli F, Rhoney DH, Black EP, Conway J, Kennedy DR. Pharmacy education crosses the rubicon. Am J Pharm Educ. 2020; 84(6):664-666. DOI: https://doi.org/10.5688/ajpe8131

2. US Department of Education. https://www.ed.gov/. Accessed August 20, 2021.

3. Engle JP. Assuring quality in pharmacy education during a time of crisis. Am J Pharm Educ. 2020; 84 (6) https://doi.org/10.5688/ajpe8135

4. Maine LL. An unparalleled spirit of collaboration amid the COVID-19 pandemic. Am J Pharm Educ. 2020; 84(6):643-645. DOI: https://doi.org/10.5688/ajpe8155

5. Hisrich RD. Kearney C. Managing innovation and entrepreneurship. Thousand Oaks, CA: SAGE Publications, Inc.; 2014.

6. Hoque F, Baer D. Everything Connects. New York: McGraw-Hill; 2014.

7. Smith P, Apple DK. Overview of Quality Learning Environments in Beyerlein SW, Holmes C, and Apple DK (Eds) Faculty Guidebook; Hampton NH: Pacific Crest; 2013; section 3.1.1.

8. Lencioni P. The five dysfunctions of a team: A leadership fable. San Francisco: Jossey-Bass; 2002.

9. Bloom TJ. The Importance of Vulnerability in Pharmacy Educators. Am J Pharm Educ. 2020; 84(7):7939; DOI: https://doi.org/10.5688/ajpe7939

10. Knowles MS. Designs for Adult Learning. Alexandria, A: American Society for Training and Development; 1995.

11. Tuckman BW. Developmental sequence in small groups. Psychol Bull. 1965; 63:384-399.

12. Kotter, JP. Leading Change. Boston, MA: Harvard Business Review Press; 2012.

13. Kubler-Ross, E. On Death and Dying: What the Dying Have to Teach Doctors, Nurses, Clergy and Their Own Families. New York, NY: Scribner; 1969.

14. Martin AJ. Academic buoyancy and academic resilience: exploring 'everyday' and 'classic' resilience in the face of academic adversity. School Psychol Int. 2013; 34:488-500. DOI: https://doi.org/10.1177\%2F0143034312472759

15. Wenger-Trayner E, Wenger-Trayner B. Introduction to communities of practice: a brief overview of the concept and its uses. Wenger-Trayner website. 2015. Accessed August 20, 2021. https://wenger-trayner.com/introductionto-communities-of-practice/

16. Karam R, Straus SG, Byers A, Kase CA, Cefalu M. The role of online communities of practice in promoting sociotechnical capital among science teachers. Education Tech Research Dev. 2018; 66:215-245. 


\section{Table 1. Initial Discussion Series - Managing Student Affairs during COVID-19}

\section{Date}

April 8, 2020

April 9, 2020

April 16, 2020

July 13,2020

August 3, 2020

Sept 16,2020

Oct 13,2020

Nov 12, 2020

\section{Topic}

Connecting with Students

Awards and Commencement

Ceremonies

Awards and Commencement Ceremonies

Return to Campus

Student Engagement

Accommodating Virtual Learners

Recruiting in a Virtual Environment

Virtual Burnout
Subtopics

Student Engagement, Social Media,

Student Organizations, Co-

Curricular Activities

Student Awards and Recognition,

Traditions, Regalia, Graduation

Gifts, Hooding, Promoting

Memories

Mental Health and Well-Being,

Career Support Services, Alumni

Engagement

Orientation, White Coat Ceremony, Social Distancing Upon Re-opening

COVID-19 Policy Enforcement, Incoming Student Community

Building, Continuing Students

Supporting: COVID-19 Cases, International Students, P1 Students,

Mental Health Concerns

What Worked Well, Challenges,

Best Practices

Student Burnout, Faculty/Staff

Burnout, Wellness Committees, In-

Person Protocols 


\section{Table 2. Responses to Key Questions from Authors Regarding the Open Discussion Series}

\section{Question}

Why was it important to have open discussions?

What do you think contributed to the success of the open discussions?

What challenges/lessons learned did we experience?

Why continue these discussions?
Member Responses

Operating procedures everywhere changed

Rapid decision making was critical

Universal need for support arose

Quick crowdsourced solutions

Multiple voices/perspectives reflecting different types

of Schools/programs

Broad audience - engaged beyond student services

Zoom platform - semi-structured, participants ability

to be seen and heard

Planned conversation starters ready, if needed

Network of similarly stressed individuals

Collaborative two-sided discussions

Balance of structure and flexibility

Have one facilitator, one chat manager, and one to

manage Zoom (having defined roles)

Video cameras promoted discussion

Facilitator broke the ice and created a "safe space"

Set ground rules at start of sessions

Moderators used text to chat behind the scenes

Limited number of slides work best

Record for people who cannot attend

Timely topics

Issues continue

Change is constant

Combine collective knowledge and expertise

New medium for best practice discussions

Timely assistance for knowledge sharing, yielding benefit over waiting for an email or annual meeting 